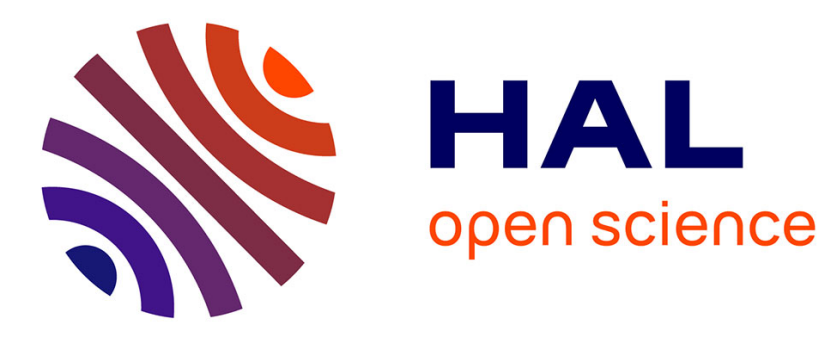

\title{
Photocatalytic degradation of indole-4-methylphenol mixture in an aqueous solution: optimization and statistical analysis
}

Smail Merabet, Aymen Amine Assadi, Abdelkrim Bouzaza, Dominique Wolbert

\section{To cite this version:}

Smail Merabet, Aymen Amine Assadi, Abdelkrim Bouzaza, Dominique Wolbert. Photocatalytic degradation of indole-4-methylphenol mixture in an aqueous solution: optimization and statistical analysis. Desalination and Water Treatment, 2016, 57 (36), pp.17039-17050. 10.1080/19443994.2015.1090920 . hal-01334051

\section{HAL Id: hal-01334051 https://hal-univ-rennes1.archives-ouvertes.fr/hal-01334051}

Submitted on 21 Jul 2016

HAL is a multi-disciplinary open access archive for the deposit and dissemination of scientific research documents, whether they are published or not. The documents may come from teaching and research institutions in France or abroad, or from public or private research centers.
L'archive ouverte pluridisciplinaire HAL, est destinée au dépôt et à la diffusion de documents scientifiques de niveau recherche, publiés ou non, émanant des établissements d'enseignement et de recherche français ou étrangers, des laboratoires publics ou privés. 


\title{
Photocatalytic degradation of indole-4-methylphenol mixture in an aqueous solution: Optimization and statistical analysis
}

\author{
Smail Merabet ${ }^{1}$, Aymen Amine Assadi ${ }^{2,3^{*}}$, Abdelkrim Bouzaza ${ }^{2,3}$, Dominique Wolbert ${ }^{2,3}$ \\ ${ }^{1}$ Laboratoire d'Hydraulique Appliquée et Environnement, Université A. Mira, 06000 Bejaïa, Algérie \\ ${ }^{2}$ Laboratoire Sciences Chimiques de Rennes - Equipe Chimie et Ingénierie des Procédés, UMR 6226 CNRS, \\ ENSCR, 11 allée de Beaulieu, 35700 Rennes, France. \\ ${ }^{3}$ Université Européenne de Bretagne, Rennes, France \\ * Corresponding author. Tel.: +33 2 23238092; fax: +33223238120. \\ E-mail address: Merabetsmail2003@yahoo.fr (S. MERABET), Aymen.assadi@ensc-rennes.fr (A. A. ASSADI*), \\ Abdelkrim.bouzaza@ensc-rennes.fr (A. BOUZAZA), Dominique.wolbert@ensc-rennes.fr (D. WOLBERT)
}

\begin{abstract}
The photocatalytic degradation of indole and 4-methylphenol mixture, using $\mathrm{ZnO}$, was studied. The optimal conditions for the degradation were determined using response surface methodology (RSM). We showed that in, our experimental domain, the quasi complete degradation of the mixture's organic constituents is possible. Moreover, we note that the effects of the entire variables are not linear. Indeed, the optimum removal conditions were determined. Thus, the optimal conditions for indole degradation, were $1.5 \mathrm{mg} / \mathrm{L}$ of catalyst concentration, $2.5 \mathrm{~L} / \mathrm{min}$ of air flow and 7.16 for $\mathrm{pH}$. For 4-methylphenol, they were 1.37 $\mathrm{mg} / \mathrm{L}$ of catalyst concentration, $2.38 \mathrm{~L} / \mathrm{min}$ of air flow and $6.96 \mathrm{of} \mathrm{pH}$. At optimized conditions the complete photocatalytic degradation was obtained at $30 \mu \mathrm{L} / \mathrm{L}$ of 4 methylphenol and $10 \mathrm{mg} / \mathrm{L}$ of indole concentration. Similarly, the optimized correlation coefficients $\mathrm{R}^{2}$ and $\mathrm{R}^{2}$ adj for a quadratic model was satisfactorily evaluated as $99.5 \%$ and $99.1 \%$ respectively with indole and there are equal to $99.7 \%$ and $99.4 \%$ respectively with 4 methylphenol. Our results reveal that the tested $\mathrm{ZnO}$ photocatalyst can be employed as a powerful tool for the pollutants degradation in wastewater.
\end{abstract}

\section{Keywords}

Photocatalysis, $\mathrm{ZnO}$, quadratic model, indole, 4-methylphenol, water treatment. 


\section{Introduction}

The pollution of the environment (water, air and waste) is one of the crucial problems which our civilization has to face. The most important ones are water pollution and treatment of wastewaters. Industry and agriculture are major contributors to soil and groundwater pollutions [1]. Most conventional water treatment processes are not destructive. They lead to a pollution transfer from one phase to another.Therefore, a different kind of pollution is faced and further treatment steps are required [1].

Advanced Oxidation Processes (AOPs) are usually considered as promising methods for wastewater treatment and more especially photocatalytic solar techniques in sunny countries such as Algeria [2]. AOPs can be used alone or in combination with biological steps in order to insure an efficient level of pollutants abatement $[3,4]$. AOPs processes lead generally to a formation of hydroxyl radicals in aqueous phases. Hydroxyl radical is able to mineralize the majority of organic compounds [5]. Among the AOPs, photocatalysis processes use semiconductors to produce hydroxyl radicals by irradiation with light of appropriate wavelengths. In fact, the photocatalysis mechanism is well known [5-7]. Under UV irradiation, an electron of the valence band is excited to the conduction band leading to the production of a positive hole $\mathrm{h}^{+}$in the valence band. On the surface of the catalyst, $\mathrm{h}^{+}$ produces a hydroxyl radical by oxidation of a water molecule adsorbed at the surface of the semiconductor. $\mathrm{h}^{+}$can also oxidize directly an adsorbed molecule by interfacial electron transfer $[8,9]$.

Generally, the most effective catalysts used for photocatalytic purification of air or water were found to be nano-sized semiconductor oxides such as $\mathrm{TiO}_{2}$ and $\mathrm{ZnO}[10,11]$, which have been proven to be efficient due to their highly reactive surface [12]. So these semi-conductors have been extensively used for photocatalytic degradation of toxic and recalcitrant chemical species present in wastewater $[13,14]$. Although $\mathrm{TiO}_{2}$ is the most often used photocatalyst for the degradation of a wide range of organic compounds, $\mathrm{ZnO}$ may represent an attractive alternative. Indeed, according to reference [15], photodegradation mechanism is similar to that of $\mathrm{TiO}_{2}$. In addition, it has been reported that $\mathrm{ZnO}$ can be more effective for the degradation of organic compounds such as 2-phenylphenol [16] and phenol [17]. Moreover, the biggest advantage of $\mathrm{ZnO}$ is that it can absorb over a wide band gap (the band gap energies of anatase- $\mathrm{TiO}_{2}$ and $\mathrm{ZnO}$ are $3.2 \mathrm{eV}$ and $3.3 \mathrm{eV}$, respectively) [18], it has a large volume-area ratio and a large initial rate of activities [19]. For this reason, $\mathrm{ZnO}$ seems to be more suitable for photocatalytic activities under sunlight irradiation. 
In this investigation, Indole and 4-methylphenol were chosen as target compounds because they are the main pollutants found in wastewater issued from cattle farm and in liquid manure. Levels as high as several $\mathrm{mg} / \mathrm{L}$ were observed in pig-breeding manure. Indole and its derivatives have unpleasant smell and can cause important damage on living organisms.

This work aims to investigate the photodegradation of indole and 4-methylphenol mixture in order to define the basic data for the design of a pilot unit of solar wastewater treatment in "Unité Avicole de Taboukert"- Algeria. Statistical approaches have been widely used in the optimisation of water treatment processes [20] especially to study the Fenton reaction [21, 22] and the treatment of industrial wastewater by photocatalysis [23]. The conventional method for optimization changing one factor successively by keeping the others constant is a time consuming and expensive process [24]. Moreover, the conventional method does not include interactive effects between experimental factors. Thus the response surface methodology is the most powerful statistical technique used to optimize and understand the performance of photocatalytic process with minimum experimental runs [24-26].

In this study, we use response surface methodology (RSM) for the experimental design under optimized conditions. We use this methodology to investigate the influence of three operating parameters on the process efficiency and to determine the optimal conditions. The studied variables were the $\mathrm{pH}$ of the suspension, the concentration of the heterogeneous photocatalyst and the air flow into the suspension containing a mixture of indole and 4-methylphenol. The study of the influence of a mixture on the photocatalytic process seems to be an interesting challenge.

\section{Materials and methods}

\subsection{Experimental materials}

Indole and 4-methylphenol were purchased from Fluka (purity > 99\%) and used as received. The commercial $\mathrm{ZnO}$ obtained from Merck (purity $>99 \%$ ) was used as received without further purification. The average grain size of the $\mathrm{ZnO}$ was estimated from powder $\mathrm{X}$-rays diffraction (XRD) pattern to be about $270 \mathrm{~nm}$ by applying the Debye-Scherrer formula to the (110) reflex line.

\subsection{Experimental set up and procedure}


All the experiments were carried out on a recirculating plant. A glass jacket reactor was used in this work with an internal volume of 0.9 liter and a UV Phillips lamp PL-L24W/4P placed in the center of the reactor inside a quartz tube. The lamp was totally immersed in the reactor to permit maximum light irradiation.

Diameter of the quartz tube (jacket) was the minimum to hold the lamp and thus the adsorption of photons light by oxygen molecules in the air around the lamp was minimized. A pump, located below the reactor, provides an adjustable circulating flow. The reactor is equipped with a water-flow jacket for regulating the temperature by means of an external circulating flow (JULABO) with an accuracy of $\pm 0,1{ }^{0} \mathrm{C}$. A cryostat was used to keep the temperature stable at $25^{\circ} \mathrm{C}$.

Air was supplied at a constant flow-rate using an air pump (micro-air compressor).The whole reactor was covered with an aluminium thin layer to prevent UV emission.

The experimental set up used in the study is shown in Fig.1.

Fig. 1: Experimental system (1: Reactor, 2: UV lamp, 3: Air pump, 4: Cryostat, 5: Water inlet, 6: Water outlet, 7: Stirrer)

The indole and 4-methylphenol solutions were prepared with bidistillated water. The natural $\mathrm{pH}$ of the solution is 6.8 and it was adjusted by adding $0.1 \mathrm{~N} \mathrm{HCl}$ or $0.1 \mathrm{~N} \mathrm{NaOH}$. The $\mathrm{pH}$ and the temperature of the solution were monitored during the runs (Inolab system). The evolution of the indole /4-methylphenol mixture concentration is followed by UV visible spectrophotometer (Shimadzu mini 1240) by sampling $0.5 \mathrm{ml}$ of solution. The sample is filtered by a $25 \mu \mathrm{m}$ micro-filter in order to eliminate any turbidity then its absorbance was measured after $5 \mathrm{~min}$ of centrifugation. Sample was free of any powder suspension.

Before irradiation with UV light (between 340 and 400 nanometers) the solution is recirculated in the dark for a period of 60 minutes in order to establish the adsorption equilibrium. During irradiation, the suspension was agitated continuously (500 tr/min) in order to maintain a homogeneous dispersion of the photocatalyst. When the adsorption equilibrium is reached, the UV lamp is turned on.

The duration of all the experiences was fixed at 130 minutes. The mixture degradation percentage is the considered response of the process study.

\section{Design of experiments and optimization}


The effects of several parameters such as the concentration of the photocatalyst, the air flow into the photoreactor and the $\mathrm{pH}$ of the suspension on the process performance were investigated.

\subsection{Model description}

The use of the design of experiments (DOE) which is a comprehensive assessment of the effectiveness of the process assumes predicting the optimal operating conditions. Using this method, one can bring out influence of several parameters and their interactions in the photocatalytic degradation process feasibility of the indole 4-methyphenol mixture. RSM (Response Surface Methodology) is an important branch of experimental design and can be considered as an efficient tool in developing new processes, optimizing their performance and improving design and formulation of new products [27-29]. It is recommended when an identification of influence of a large numbers of variables of the experimental system is needed $[27,28]$.

Many studies using approaches leading to models with a single variable or experiments are carried out by varying one parameter while all others remain constant. An alternative to this approach is the factorial experimental design which is a statistical tool that allows the simultaneous change of several variables [29-32]. This leads to optimize and to highlight the influence of different factors and their interactions in the feasibility study of photocatalytic oxidation process [30-35].

Our approach aims at studying and modelling the process of photodegradation by using the response surface methodology (RSM). This approach is based on a mathematical model of second order with three independent variables $\mathrm{X}_{1}$ (Concentration of the photocatalyst), $\mathrm{X}_{2}$ (airflow into the photoreactor) and $\mathrm{X}_{3} \mathrm{pH}$ of the indole-4-méthylphenol mixture.

All the results were treated and interpreted using a MICROSOFT EXCEL and the statistic software SATISTICA 6.0. The determination of the effects of these parameters on the mixture of indole -4-methylphenol photodegradation (response) was carried out by using the central composite experimental design (CCD) [30-36]. Concentration of catalyst, $\mathrm{pH}$ and air flow were chosen as independent variables and the percentage of photodegradation as the dependent output response variable. Independent variables, experimental ranges and levels of the indole-4-methylphenol mixtures are given in Table 1. The formulated design matrix which is shown in Table 2 is a response surface central composite design consisting of 20 sets of 
coded conditions [30-35]. It comprises a full replication of $2^{3}(=8)$ factorial design with appending six center points and others six experiments of axial star points of codified values \pm $a=\left(\mathrm{N}_{\mathrm{F}}\right)^{1 / 4}=1.681[30-36]$. All the variables are coded at three levels: intermediate level (0) which constitute the center points and the lowest $(-1)$ or highest $(+1)$ level $[\mathbf{3 1}, \mathbf{3 4}, \mathbf{3 5}]$. Thus, a 20 experimental runs were checked in order to estimate the linear, quadratic and two-way interactive effects of tested variable on the percentage photodegradation. Experimental plan which illustrate the coded value and the photodegradation percentage of indole-4methylphenol mixture is given Table 2. For statistical calculations, the variables $X_{i}$ were coded as $x_{i}$ according to the following relationship:

$$
x_{i}=\left(\mathrm{X}_{\mathrm{i}}-\mathrm{X}_{\mathrm{i} 0}\right) / \delta \mathrm{X}_{\mathrm{i}}
$$

where $x_{i}, X_{i}$ are the coded and natural values of independent variables respectively, $X_{i 0}$ the natural value of the $\mathrm{i}^{\text {th }}$ independent variable to focus $\delta \mathrm{X}_{\mathrm{i}}$ and the value of no corresponding change [30-35].

\section{Table.1: Ranges and levels of independent variables experimental test for photodegradation percent of the mixture indole-4-methylphenol}

Based on the works of Ravikumar et al. and Korbahti et al., in order to evaluate the pure error, six replications of experiments were carried out in randomized order as required in many design procedures $[\mathbf{3 0}, \mathbf{3 1}, \mathbf{3 5}]$. The process performance was investigated by analysing the response of photodegradation percent of indole - 4-methylphenol mixture.

Therefore, to optimize the process the responses can be simply related to chosen factors by linear or quadratic models [30-35]. A quadratic model which also introduces the linear model is defined as:

$$
Y=\beta_{0}+\sum_{i=1}^{k} \beta_{i} . x_{i}+\sum_{i=1}^{k} \beta_{i i .} x_{i}^{2}+\sum_{i=1}^{k-1} \sum_{j=i+1}^{k} \beta_{i j} x_{i} x_{j}+e
$$

Where $Y$ is the observed response, $\beta_{0}, \beta_{i}, \beta_{i j}$ and $\beta_{i i}$ are constant term, the coefficients of linear effects, interactions and quadratic terms respectively. $x_{i}$ and $x_{j}$ represent the variables and $e_{i}$ the error. The fit quality of polynomial model was identified by the determination of $\mathrm{R}^{2}$ and $\mathrm{R}^{2}$ adj coefficients [30-35].

\subsection{Discussion of modelling results}


Mixture of indole-4-methylphenol solution of $30 \mu \mathrm{L} / \mathrm{L}$ and $10 \mathrm{mg} / \mathrm{L}$ concentration was prepared and submitted to UV light with the presence of a given amount of a catalyst. It was noted that the absorption value, which measures pollutant concentration, became minor with irradiation time, thus indicating the photodegradation of mixture solution. The decrease in absorption value of mixture solution can be related in terms of photodegradation percentage to the response as follow:

$$
y(\%)=\left[\left(\mathrm{C}_{0}-\mathrm{C}_{\mathrm{t}}\right) / \mathrm{C}_{0}\right] \times 100
$$

were $\mathrm{C}_{0}$ and $\mathrm{C}_{\mathrm{t}}$ represent respectively the initial and the final concentration of pollutant.

This response (objective function) was the degradation percentage of the mixture as determined after 130 minutes of irradiation. The complete experimental design including experimental responses is given Table 2.

\section{Table.2: Full factorial central composite design matrix for indole and 4-methylphenol}

The experimental design results were investigated by STATISTICA 6.0 which is statistical software to evaluate the response of the dependent variable in all experiments. Briefly, the regression model equation relating the percentage of photodegradation and process parameters were developed and given in Eqs (4) and (5) for indole and 4-methylphenol respectively:

$$
\begin{aligned}
\mathrm{Y}_{\text {pred }}(\text { Indole })=90.054+ & 10.177 x_{1}+11.825 x_{2}+23.061 x_{3}-1.056 x_{1} x_{2}-3.081 x_{1} x_{3} \\
& -5.491 x_{2} x_{3}-5.505 x_{1}^{2}-4.936 x_{2}^{2}-15.370 x_{3}^{2} \\
Y_{\text {pred }}(4-m e t h y l p h e n o l)= & 93.480+9.749 x_{1}+11.244 x_{2}+21.785 x_{3}-2.176 x_{1} x_{2} \\
& -3.236 x_{1} x_{3}-4.964 x_{2} x_{3}-4.901 x_{1}^{2}-5.075 x_{2}^{2}-14.735 x_{3}^{2}
\end{aligned}
$$

The mean value of the six central points (90.05\% degradation for indole) and (93.48\% for 4methylphenol) is very close to that of $\beta_{0}$. This relatively high value seems to be logical due to that our target is the quasi-complete degradation of indole and 4-methylphenol mixture. We note that in our case the definition of the central point of the experimental domain was chosen on the basis of preliminary investigations [30-35]. 


\section{Fig. 2: Predicted values compared with experimental results for both pollutants indole}

(a) and 4-methylphenol (b).

We used the value of $\mathrm{R}^{2}$ coefficient to express the fit quality of the polynomial model. On the other hand the statistical significance was evaluated by Fisher's F-test and Student's t-test (Analysis of Variance, ANOVA).

The level of significance was given as values of $P$ less than 0.0001 . The predicted values are close to the observed values (see Fig.2). Thus a second-order polynomial can correlate well the experimental results. The high value obtained of indole and 4-methylphenol $\mathrm{R}^{2}$ coefficients are respectively 99.5 and $99.7 \%$. This means that $99.5 \%$ and $99.7 \%$ of the variation in the photocatalytic degradation performance of pollutants are explained by the independents variables which are highly significant. This seems to be logical due to the importance of these experimental parameters on the process efficiency. We can note that the $\mathrm{pH}$ of the mixture has higher influence than catalyst concentration and air flow. It is well known [37] that $\mathrm{pH}$ influences surface charges properties of the photocatalyst and therefore the adsorption of the pollutant and the size of particles aggregate. Catalyst concentration and air flow seem to have the same importance for the two pollutants.

High $\mathrm{R}_{\text {adj }}^{2}$ coefficients which are equal to 99.4 and 99.1 for 4-methylphenol and indole respectively allow us to confirm that the predicted values are close to the experiments. According to ANOVA tests (Table.3) the obtained F-values for all regressions were higher. In fact, the ANOVA analysis is a statistical technique that subdivides the total variation in a set of data into component parts [37]. The large value of $\mathrm{F}$ indicates that most of the variation in the response can be explained by the second order polynomial [30-36]. Moreover, the associated $P$ value is used to quantify whether F-value is large enough to indicate statistical significance. Indeed, when this value is lower than 0.01 , it indicates that the model can be considered as statistically significant $[37,38]$.

Here, the use of F-Fisher value which is obtained by the ratio of the regression variance to residual variance $\left(\mathrm{F}\right.$-value $=\mathrm{S}_{\text {reg }}{ }^{2} \mathrm{~S}_{\text {err }}$ ) demonstrates that the model is highly significant at $1 \%[30-35]$. This is justified by the fact that the value of the F calculated is much larger than the value of $\mathrm{F}$ tabulated.

For the regression of indole:

$$
\mathrm{F}_{0.01 ; 9 ; 10}=\mathrm{S}^{2}{ }_{\text {reg }} / \mathrm{S}_{\text {err }}^{2}=227.85 \gg \mathrm{F}_{0.01 ; 9 ; 10(\text { tabulated })}=4.94
$$

and regression for 4-methylphenol we have: 


$$
\mathrm{F}_{0.01 ; 9 ; 10}=\mathrm{S}^{2}{ }_{\text {reg }} / \mathrm{S}^{2} \text { err }=345.90 \gg \mathrm{F}_{0.01 ; 9 ; 10(\text { tabulated })}=4.94
$$

This indicated that the fitted model exhibits lack of fit with (P-value $=0.000$ and $\mathrm{P}$-value $=0.001$ for indole and 4-methylphenol respectively).

In order to evaluate the pure error, the designed experiments with six replications were carried out in randomized order as based on several design procedures [30-35].

Table.3 (ANOVA) of removal efficiency for indole- 4-methylphenol mixture.

Student's t-test was used to analyze obtained results in order to determine the significance of the regression coefficients of the variables. On the other hand the $P$-values were used as a tool to determine the significance of the variables. The regression coefficient, $\mathrm{t}$ - and $P$-values for all linear, quadratic and interaction effects of the variables are given in Table 4 and 5.

\section{Table 4: Estimated regression coefficients and corresponding $\boldsymbol{t}$ and $\boldsymbol{P}$-value for indole}

Table 5: Estimated regression coefficients and corresponding $\boldsymbol{t}$ and $\boldsymbol{P}$-value for 4methylphenol

The interaction effects plot which describes the influence of each variable on the photodegradation of indole and 4-methylphenol mixture respectively is given in Fig. (3) and (4).

The photodegradation is affected by the quadratic terms in order of importance $\mathrm{x}_{3}(\mathrm{pH}$ mixture), $\mathrm{x}_{2}$ (air flow) and $\mathrm{x}_{1}$ (the concentration of catalyst). This adverse effect is explained by the fact that over the $\mathrm{pH}$ of the solution, air flow and catalyst concentration longer decreasing the photodegradation of indole and 4-methylphenol mixture decreases also. On the other hand, the interactions terms have a small influence compared to quadratic terms. Figs. 3 and 4 show that the interaction of air flow and $\mathrm{pH}$ of the solution is as important as the air flow and the catalyst comes indeed the latter the lowest among the airflow and the concentration of catalyst.

Fig.3: Interaction effects plot for removal indole

Fig.4: Interaction effects plot for removal 4-methylphenol 
The linear, quadratic and interactions effects are significant for both responses. Except the interactions $\left(\mathrm{x}_{1} \times \mathrm{x}_{2}\right)$ for the two responses, where there is a weak interaction particularly between $\left(\mathrm{x}_{1} \times \mathrm{x}_{2}\right)$ for regression of 4-methylphenol. This is confirmed by the value of the interaction effect of concentration of $\mathrm{ZnO}$ and air flow $(P=0.290$ for indole and $P=0.014$ for 4-methylphenol) and the response contour plots of mutual interactions among this variables $\left(\begin{array}{ll}\mathrm{x}_{1} & \mathrm{x}_{2}\end{array}\right)$ was found almost circular. With a high catalyst concentration and a low rate of air injected into the solution, set at the average interval in the field of experimental chosen degradation is a major achievement for indole and 4-methylphenol mixture.

The photodegradation is affected by the quadratic terms. On the other hand, interactions terms have a small influence compared to quadratic terms for both responses.

Graphs of surface and contours can be considered as simple method which leads to optimize the wastewater treatment and to identify the variables interactions $[\mathbf{3 0 - 3 5}, \mathbf{4 0 , 4 1}$ (see Fig.5 and 6). For the degradation of indole-4-methylphenol mixture each curve can represent an infinite number of combinations between two variables when the third variable is kept at a central level for all combinations. The response contour plots of mutual interactions were found to be elliptical for $\mathrm{pH}$ and $\mathrm{ZnO}$ and also for air flow and $\mathrm{ZnO}$. The similar types of trends were found in literature [40-43]. Via Fig. 5, a performance of $99.9 \%$ of indole degradation can be obtained for a $1.50 \mathrm{mg} / \mathrm{L}$ of catalyst concentration and around $2.5 \mathrm{~L} / \mathrm{min}$ of airflow with a pH attached to the central value. For an air flow of $2.40 \mathrm{~L} / \mathrm{min}$ and a catalyst concentration of $1.35 \mathrm{mg} / \mathrm{L}$, in the range of experimental chosen, a percentage of photodegradation around $100 \%$ of 4-methylphenol (Fig. 6) can be reached at $\mathrm{pH}$ set at the average. The optimum values drawn from these figures are in close agreement with those obtained by optimizing the regression model Eq. (3) and (4).

On the other hand, the interaction between the two factors, airflow and $\mathrm{ZnO}$, seems to be negligible.

Fig.5: Graphs of surface and contours plots of indole removal (\%) showing interactive effect of two factors when the third is fixed at an average.

Fig.6: Graphs of surface and contours plots of 4-methylphenol removal (\%) showing interactive effect of two factors when the third is fixed at an average. 
The influence of the variables, $x_{1}, x_{2}$ and $x_{3}$, ( $\mathrm{ZnO}$ concentration, air flow and $\mathrm{pH}$ respectively) on the photodegradation can be observed from the contour plot. In fact, Figs. 5 and 6 show that all three variables affect the percentage of the photodegradation of the indole and 4methylphenol mixture. Indeed, the angle of inclination of the principal axis in Fig. 5 is slight, indicating that photodegradation is more dependent on $\mathrm{pH}$ than on $\mathrm{ZnO}$ concentration. Moreover the inclination angle is more towards $\mathrm{pH}$ (Fig. 5), indicating that the process is more dependent on $\mathrm{pH}$ than on air flow. Also we see that mutual interactions among this variables $\left(x_{1}, x_{2}\right)$ was found almost circular were the angle is slightly toward air flow than $\mathrm{ZnO}$ concentration. The same behavior is observed with the 4-methylphenol (Fig. 6).

The quadratic models obtained reflect adequately the process of photocatalytic degradation of indole and 4-méthylphenol mixture. In fact, the optimum values drawn from Fig. 5 and 6 are in close agreement with those obtained by optimizing the regression model. This confirms that the design of experiments could be effectively used to optimize the variables of photocatalytic process of pollutants mixture.

\section{Conclusions}

The goal of this paper was to investigate the photocatalytic degradation of indole and 4methylphenol mixture with the presence of $\mathrm{ZnO}$ photocatalyst using response surface methodology (RSM). Two predicting models based on multiple regressions were tested by the method of analysis (ANOVA). This analysis indicates that the models are significant and correlate well the experimental results. We can note that the process efficiency is more dependent on the $\mathrm{pH}$ of the mixture than on $\mathrm{ZnO}$ concentration. On the other hand, more than $99 \%$ of the process performance is due to independent variables $(\mathrm{pH}$, catalyst concentration and air flow).

We have demonstrated clearly the potential of a photocatalytic process for the quasi complete degradation of indole-4-metyhlphenol mixture in wastewater. The optimum values of the process variables are determined thanks to graphs of surface and contours. When one of experimental variable is kept at central level, we have the possibility to reach the optimum values for the other two variables. Moreover, the methodology (RSM) which gives us a large amount of information with a small amount of experimentation was able to design and optimize the photocatalytic degradation process. 
Additionally, the contour and surface plots confirm that the design of experiments concept could be effectively used to optimize the process variable with statistical design of experiments.

\section{Acknowledgment}

One of the authors (S. M.) thanks the University of Bejaia (Algeria) for financial support. 


\section{References}

[1] I. K. Konstantinou and T.A. Albanis, $\mathrm{TiO}_{2}$-assisted photocatalytic degradation of azo dyes in aqueous solution: kinetic and mechanistic investigations: a review, Appl. Catal. B. Environ., 49 (2004) 1-14.

[2] T. Van Gerven, G. Mul, J. Moulin and A. Stankiewicz, A review of intensification of photocatalytic processes, Chem. Eng. Process, 46 (2007) 781 -789.

[3] J. Wiszniowski, D. Robert, J. Surmacz-Gorska, K. Miksch, M. Sixto and J. V. Weber, Solar photocatalytic degradation of humic acids as a model of organic compounds of landfill leachate in pilot-plant experiments: influence of inorganic salts, Appl. Catal. B.: Environ., 53 (2004) 127-137.

[4] J. Bohdziewicz, M. Bodzek and J. Gorska, Application of pressure-driven membrane techniques to biological treatment of landfill leachate. Process Biochem., 36 (2001) 641-646.

[5] M. I. Badawy, M. E.M. Ali, M.Y. Ghaly and M. A. El-Missiry, Mesoporous simonkolleite- $\mathrm{TiO}_{2}$ nanostructured composite for simultaneous photocatalytic hydrogen production and dye decontamination, Process Saf. Environ., 94 (2015) 11-17

[6] A. N. Ökte, D. Tuncel, A.H. Pekcan and T. Özden, Characteristics of iron-loaded $\mathrm{TiO}_{2-}$ supported montmorillonite catalysts: $\beta$-Naphthol degradation under UV-A irradiation, J. Chem. Technol. and Biot., 89 (2014) 1155-1167.

[7] T. E. Agustina, H. M.Ang and V. K. Vareek, A review of synergistic effect of photocatalysis and ozonation on wastewater treatment, J. Photochem. Photobiol.C., 6 (2005) 264-273.

[8] P. A. Deveau, F. Arsac, P. X. Thivel, C. Ferronato, F. Delpech, J. M. Chovelon, P. Kaluzny and C. Monnet, Different methods in $\mathrm{TiO}_{2}$ photodegradation mechanism studies: Gaseous and $\mathrm{TiO}_{2}$ - absorbed phases, J. Hazard. Mater., 144 (2007) 692-697. 
[9] Y. Dong, D. Tang and Ch. Li, Photocatalytic oxidation of methyl orange in water phase by immobilized $\mathrm{TiO}_{2}$-carbon nanotube nanocomposite photocatalyst, Appl. Surf. Sci., 296 (2014) $1-7$

[10] V. Romero, F. Méndez-Arriaga, P. Marco, J. Giménez and S. Esplugas, Comparing the photocatalytic oxidation of Metoprolol in a solarbox and a solar pilot plant reactor, Chem. Eng. Journal, 254 (2014) 17-29,

[11] P.B. Amama, K. Itoh and M. Murabayashi, Photocatalytic degradation of trichloroethylene in dry and humid atmospheres: role of gas-phase reactions, J. Mol. Catal. A: Chem., 217 (2004) 109-115

[12] C.B. Almquist and P. Biswas, Role of synthesis method and particle size of nanostructured $\mathrm{TiO}_{2}$ on its photoactivity. J. Catal., 212 (2002) 145-156

[13] V. Vaiano, G. Iervolino, D. Sannino, L. Rizzo, G. Sarno and A. Farina, Enhanced photocatalytic oxidation of arsenite to arsenate in water solutions by a new catalyst based on $\mathrm{MoO}_{\mathrm{x}}$ supported on $\mathrm{TiO}_{2}$, Appl. Catal. B.: Environ., 160-161 (2014) 247-253.

[14] P. Xu, G. M. Zeng, D. L. Huang, Ch. L. Feng, Sh. Hu, M. H. Zhao, C. Lai, Zh. Wei, Ch. Huang, G. X. Xie, Zh and F. Liu, Use of iron oxide nanomaterials in wastewater treatment: A review, Sci. Total Environ., 424 (2012) 1-10

[15] K. Pirkaniniemi and M. Sillanpaa, Heterogeneous water phase catalysis as an environmental application: a review, Chemosphere, 48 (2002) 1047-1060.

[16] İ. Altın and M. Sökmen, Buoyant photocatalyst based on $\mathrm{ZnO}$ immobilized on polystyrene beads for pollution treatment, Clean Soil AirWater Article in press doi: [10.1002/clen.201400303].

[17] G. Marci, V. Augugliaro, M.J.L. Munoz, C. Martin, L. Palmisano, V. Rives, M. Schiavello,R.J.D. Tilley and A.M. Venezia, Preparation characterization and photocatalytic 
activity of polycrystalline $\mathrm{ZnO} / \mathrm{TiO}_{2}$ systems. 1. Surface and bulk characterization, J. Phys. Chem. B, 105 (2001) 1026-1032.

[18] A. Rezaee, H. Masoumbeigi, R. D. Ch. Soltani, A. R. Khataee and S. Hashemiyan, Photocatalytic decolorization of methylene blue using immobilized $\mathrm{ZnO}$ nanoparticles prepared by solution combustion method, Desalin. Wat. Treat., 44 (2012)1-3.

[19] R. Darvishi, Ch. Soltani, A. Rezaee, A.R. Khataee, M. Safari, Photocatalytic process by immobilized carbon black/ZnO nanocomposite for dye removal from aqueous medium: Optimization by response surface methodology, J. Ind. Eng. Chem., 20 (2014) 1861-1868

[20] M, Sleiman, D.Vildozo, C. Ferronato. and J.-M Chovelon. Photocatalytic degradation of azo dye metanil yelow: optimisation and kinetic modeling using a chemometric approach, Appl. Catal. B.: Environ., 77 (2007) 1-11.

[21] F. Herrera, A. Lopez, J. Kiwi, Photochemically activated degradation of reactive dyes. Statistical modelling of the reactor performance, J. Photochem. Photobiol. A., 135 (2000) 4551.

[22] E. Oliveros, O. Legrini, M. Hohl, T. Müller and A.M. Braun, Large scale development of a light-enhanced fenton reaction by optimal experimental design, Wat. Sci. Technol., 35 (1997) 223-230.

[23] M. N. Chong, B. Jin, C. W.K. Chow and C. Saint, Recent developments in photocatalytic water treatment technology: A review, Water Res., 44 (2010) 2997-3027

[24] I.A. Appavoo, J. Hu, Y. Huang, S. F. Y. Li and S. L. Ong, Response surface modeling of Carbamazepine (CBZ) removal by Graphene-P25 nanocomposites/UVA process using central composite design, Water Res., 57 (2014) 270-279

[25] I.H.Cho and K.D. Zoh, Photocatalytic degradation of azo dye (Reactive Red 120) in $\mathrm{TiO}_{2} / \mathrm{UV}$ system: optimization and modeling using a response surface methodology (RSM) based on the central composite design, Dyes Pigments, 75 (2007) 533-543. 
[26] H-L Liu and Y-R Chiou, Optimal decolorization efficiency of Reactive Red 239 by $\mathrm{UV} / \mathrm{TiO}_{2}$ photocatalytic process coupled with response surface methodology, Chem. Eng. J., 112 (2005) 173-179

[27] A. Danion, C. Bordes, J. Disdier, J.V. Gauvrit, C. Guillard,P. Lanteri and N. Jaffrezic, Optimization of a single $\mathrm{TiO}_{2}$ coated optical fiber reactor using experimental design, $\mathrm{J}$. Photochem. Photobiol. A. 168 (2004) 161-167.

[28] I.H Cho and K.D. Zoh, Photocatalytic degradation of azodyes (reactive Red 120) in $\mathrm{TiO}_{2} / \mathrm{UV}$ system. Optimization and modeling using a response surface methodology (RSM) based on central composite design. Dyes Pigments, 75 (2007) 533-543

[29] J. Fernandez, J. Kiwi, C. Lizama, J. Freer, J. Baeza and H.D. Mansilla, Factorial experimental design of Orange II photocatalytic discolouration, J. Photochem. Photobiol. A ., 151 (2002) 213-219.

[30] B.K. Korbahti, Response surface optimization of electrochemical treatment of textile dye wastewater. J. Hazard. Mater., 145(2007) 277-286.

[31] K. Ravikumar, K. Pakshirajan, T. Swaminathan, K. Balu, Optimization of batch process parameters using response surface methodology for dye removal by a novel adsorbent. Chem. Eng. J., 105(2005), 131-138.

[32] M. Rajasimman, R. Sangeetha and P. Karthic, Statistical optimization of process parameters for the extraction of chromium (VI) from pharmaceutical wastewater by emulsion liquid membrane. Chem. Eng. J., 150 (2009) 275-279.

[33]A. Aleboyeh, N. Daneshvar and M.B. Kasiri, Optimization of C.I. Acid Red 14 azo dye removal by electrocoagulation batch process with response surface methodology, Chem. Eng. Process, 47 (2008) 827-832. 
[34] A.Ozer, G.Gurbuz, A.C. Alimli, B.K Korbahti, Biosorption of copper (II) ions on Enteromorpha prolifera: Application of response surface methodology, Chem. Eng. J., 146 (2009) 377-387.

[35] B.K. Korbahti and M.A. Rauf, Application of response surface analysis to the photolytic degradation of Basic Red 2 dye, Chem, Eng. J., 138 (2008) 166-171

[36] G.E.P. Box, W.G. Hunter and J.S. Hunter, Statistics for Experimenters: An Introduction to Design, Data Analysis and Model Building, Wiley, New York, 1978.

[37] S. Merabet, A. Bouzaza, D. Wolbert, Photocatalytic degradation of indole in a circulating upflow reactor by $\mathrm{UV} / \mathrm{TiO}_{2}$ process-Influence of some operating parameters, Journal of Hazardous Materials, 166 (2009) 1244-1249

[38] S. H. Sh. Chan, Ta Y. Wu, J. Ch. Juan and Ch. Y. The recent developments of metal oxide semiconductors as photocatalysts in advanced oxidation processes (AOPs) for treatment of dye waste-water, J. Chem. Technol. Biot., 86 (2011) 1130-1158.

[39] H.M. Kim, Kim J.G., J.D. Cho, J.W. Hong, Optimization and characterization of UVcurable adhesives for optical communication by response surface methodology, Polym. Test., 22 (2003) 899-906.

[40] D.C. Montgomery, Design and analysis of experiments. 3rd ed. New York: Wiley; 1991.

[41] G. Box and W.G. Hunter, Statistics for Experiments: An Introduction to Design, Data Analysis and Model Building, Wiley Interscience, 1987.

[42] D.C. Montgomry, Design and Analysis of Experiments, 5th ed., John Wiley and Sons, New York, 2001

[43] V. Koutantou, M. Kostadima, E. Chatzisymeon, Z. Frontistis, V. Binas, D. Venieri and D. Mantzavinos, Solar photocatalytic decomposition of estrogens over immobilized zinc oxide, Catal. Today, 209 (2013) 66-73 


\section{Tables}

Table.1: Ranges and levels of independent variables experimental test for photodegradation percent of the mixture indole-4-methylphenol

Table.2. Full factorial central composite design matrix for indole and 4-methylphenol

Table.3 (ANOVA) of removal efficiency for mixture indole- 4-methylphenol (p-cresol)

Table 4: Estimated regression coefficients and corresponding $t$ and $P$-value for indole

Table 5: Estimated regression coefficients and corresponding $t$ and $P$-value for 4methylphenol 
Table.1: Ranges and levels of independent variables experimental test for photodegradation percent of the mixture indole-4-methylphenol

\begin{tabular}{|c|c|c|c|c|c|}
\hline \multirow{2}{*}{ Independent variables } & \multicolumn{5}{|c|}{ Ranges and levels } \\
\cline { 2 - 6 } & $-\alpha$ & -1 & 0 & +1 & $+\alpha$ \\
\hline $\begin{array}{c}\text { Concentration of catalyst }\left(\mathrm{X}_{1}\right) \\
(\mathrm{g} / \mathrm{L})\end{array}$ & 0.5 & 0.804 & 1.25 & 1.696 & 2 \\
\hline & & & & & \\
\hline Air flow $\left(\mathrm{X}_{2}\right)(\mathrm{L} / \mathrm{min})$ & 0.5 & 0.91 & 1.5 & 2.09 & 2.5 \\
\hline $\mathrm{pH}$ of mixture $\left(\mathrm{X}_{3}\right)$ & 4 & 5.21 & 7 & 8.78 & 10 \\
\hline
\end{tabular}


Table.2. Full factorial central composite design matrix for indole and 4-methylphenol

\begin{tabular}{|c|c|c|c|c|c|c|c|}
\hline \multirow[b]{2}{*}{ No Exp. } & \multicolumn{3}{|c|}{ Code variables } & \multicolumn{2}{|c|}{$\begin{array}{l}\text { Removal efficiency } \\
\text { (Y\%) of indole }\end{array}$} & \multicolumn{2}{|c|}{$\begin{array}{l}\text { Removal efficiency } \\
\text { (Y\%) of 4-methylpheno }\end{array}$} \\
\hline & $\begin{array}{c}\mathrm{x}_{1} \\
(\mathrm{ZnO})\end{array}$ & $\begin{array}{c}\mathrm{X}_{2} \\
\left(\mathrm{Q}_{\text {air }}\right)\end{array}$ & $\begin{array}{c}\mathrm{x}_{3} \\
(\mathrm{pH})\end{array}$ & Obs & Pred & Obs & Pred \\
\hline 1 & -1 & 1 & -1 & 47.09 & 46.2955 & 52.13 & 52.382 \\
\hline 2 & 0 & 0 & 0 & 90.01 & 90.0543 & 93.10 & 93.480 \\
\hline 3 & 0 & 0 & 0 & 89.85 & 90.0543 & 93.04 & 93.480 \\
\hline 4 & 1 & 1 & -1 & 67.99 & 70.7001 & 71.75 & 74.000 \\
\hline 5 & 0 & $-\alpha$ & 0 & 54.07 & 56.2065 & 58.13 & 60.216 \\
\hline 6 & 0 & 0 & 0 & 89.93 & 90.0543 & 93.06 & 93.480 \\
\hline 7 & 0 & 0 & $-\alpha$ & 8.50 & 7.7986 & 16.25 & 15.164 \\
\hline 8 & $\alpha$ & 0 & 0 & 95.30 & 91.5990 & 98.50 & 96.012 \\
\hline 9 & 1 & 1 & 1 & 97.95 & 99.6778 & 99.74 & 98,997 \\
\hline 10 & 0 & 0 & 0 & 90.25 & 90.0543 & 93.88 & 93.480 \\
\hline 11 & $-\alpha$ & 0 & 0 & 53.00 & 57.3668 & 60.50 & 63.221 \\
\hline 12 & -1 & 1 & 1 & 89.15 & 87.5982 & 93.45 & 92.498 \\
\hline 13 & 0 & 0 & $\alpha$ & 84.00 & 85.3673 & 87.12 & 88.440 \\
\hline 14 & -1 & -1 & 1 & 76.00 & 72.8191 & 78.00 & 75.585 \\
\hline 15 & 0 & $\alpha$ & 0 & 97.45 & 95.9793 & 99.89 & 98.037 \\
\hline 16 & 0 & 0 & 0 & 90.10 & 90.543 & 93.75 & 93.480 \\
\hline 17 & 1 & -1 & -1 & 37.10 & 38.1810 & 45.15 & 45.937 \\
\hline 18 & -1 & -1 & -1 & 11.75 & 9.5514 & 17.21 & 15.614 \\
\hline 19 & 0 & 0 & 0 & 90.30 & 90.0543 & 94.09 & 93.480 \\
\hline 20 & 1 & -1 & 1 & 88.80 & 89.1237 & 93.38 & 92.962 \\
\hline
\end{tabular}


Table.3 (ANOVA) of removal efficiency for mixture indole- 4-methylphenol. (p-cresol)

\begin{tabular}{|c|c|c|c|c|c|c|c|c|c|}
\hline \multirow{2}{*}{ Source } & \multirow{2}{*}{$\begin{array}{l}\text { Degree } \\
\text { Of } \\
\text { freedom }\end{array}$} & \multicolumn{2}{|c|}{$\begin{array}{c}\text { Sum of squares } \\
\text { (SS) }\end{array}$} & \multicolumn{2}{|c|}{$\begin{array}{c}\text { Mean square } \\
\text { (MS) }\end{array}$} & \multicolumn{2}{|c|}{ F-value } & \multicolumn{2}{|c|}{ P-value } \\
\hline & & Indole & P-cresol & Indole & P-cresol & Indole & P-cresol & Indole & P-cresol \\
\hline Model & 9 & 14684.5 & 13286.1 & 1631.61 & 1476.23 & 227.85 & 345.90 & 0.000 & 0.000 \\
\hline Linear & 3 & 10587.1 & 9506.2 & 3529.03 & 3168.72 & 492.81 & 742.48 & 0.000 & 0.000 \\
\hline Square & 3 & 3771.3 & 3461.1 & 1257.09 & 1153.71 & 175.55 & 270.33 & 0.000 & 0.000 \\
\hline Interaction & 3 & 326.1 & 318.8 & 108.70 & 106.26 & 15.18 & 24.90 & 0.000 & 0.000 \\
\hline $\begin{array}{c}\text { Residual } \\
\text { error }\end{array}$ & 10 & 71.6 & 42.7 & 7.16 & 4.27 & - & - & - & - \\
\hline Lack of fit & 5 & 71.5 & 41.6 & 14.29 & 8.31 & 452.99 & 37.13 & 0.000 & 0.001 \\
\hline Pure error & 5 & 0.2 & 1.1 & 0.03 & 0.22 & - & - & - & - \\
\hline Total & 19 & 14756.1 & 13328.7 & - & - & - & - & - & - \\
\hline
\end{tabular}


Table 4: Estimated regression coefficients and corresponding $t$ and P-value for indole

\begin{tabular}{|c|c|c|c|c|}
\hline Term & $\begin{array}{c}\text { Coefficient of } \\
\text { regression }\end{array}$ & Standard Error & t-value & P-value \\
\hline Constant & 90.054 & 1.0914 & 82.512 & $0.000(\mathrm{a})$ \\
\hline $\mathrm{x}_{1}$ & 10.177 & 0.7241 & 14.055 & $0.000(\mathrm{a})$ \\
\hline $\mathrm{x}_{2}$ & 11.825 & 0.7241 & 16.326 & $0.000(\mathrm{a})$ \\
\hline $\mathrm{x}_{3}$ & 23.061 & 0.7241 & 31.847 & $0.000(\mathrm{a})$ \\
\hline $\mathrm{x}_{1} \times \mathrm{x}_{1}$ & -5.505 & 0.7049 & -7.810 & $0.000(\mathrm{a})$ \\
\hline $\mathrm{x}_{2} \times \mathrm{x}_{2}$ & -4.936 & 0.7049 & -7.002 & $0.000(\mathrm{a})$ \\
\hline $\mathrm{x}_{3} \times \mathrm{x}_{3}$ & -15.370 & 0.7049 & -21.803 & $0.000(\mathrm{a})$ \\
\hline $\mathrm{x}_{1} \times \mathrm{x}_{2}$ & -1.056 & 0.9461 & -1.116 & $0.290(\mathrm{~b})$ \\
\hline $\mathrm{x}_{1} \times \mathrm{x}_{3}$ & -3.081 & 0.9461 & -3.252 & $0.009(\mathrm{~b})$ \\
\hline $\mathrm{x}_{2} \times \mathrm{x}_{3}$ & -5.491 & 0.9461 & -5.804 & $0.000(\mathrm{a})$ \\
\hline
\end{tabular}

(a) P-value $<0.001$.

(b) In bold, coefficient statistically non-significant. 
Table 5: Estimated regression coefficients and corresponding $\boldsymbol{t}$ and $\boldsymbol{P}$-value for 4methylphenol

\begin{tabular}{|c|c|c|c|c|}
\hline Term & $\begin{array}{c}\text { Coefficient of } \\
\text { regression }\end{array}$ & Standard Error & t-value & P-value \\
\hline Constant & 93.480 & 0.8425 & 110.949 & 0.000 (a) \\
\hline $\mathrm{x}_{1}$ & 9.749 & 0.5590 & 17.439 & 0.000 (a) \\
\hline $\mathrm{x}_{2}$ & 11.244 & 0.5590 & 20.115 & 0.000 (a) \\
\hline $\mathrm{x}_{3}$ & 21.785 & 0.5590 & 38.971 & 0.000 (a) \\
\hline $\mathrm{x}_{1} \times \mathrm{x}_{1}$ & -4.904 & 0.5442 & -9.007 & 0.000 (a) \\
\hline $\mathrm{x}_{2} \times \mathrm{x}_{2}$ & -5.075 & 0.5442 & -9.325 & 0.000 (a) \\
\hline $\mathrm{x}_{3} \times \mathrm{x}_{3}$ & -14.735 & 0.5442 & -27.078 & 0.000 (a) \\
\hline $\mathrm{x}_{1} \times \mathrm{x}_{2}$ & -2.171 & 0.7304 & -2.980 & 0.014 (b) \\
\hline $\mathrm{x}_{1} \times \mathrm{x}_{3}$ & -3.236 & 0.7304 & -4.431 & 0.001 (b) \\
\hline $\mathrm{x}_{2} \times \mathrm{x}_{3}$ & 4.964 & 0.7304 & -6.796 & 0.000 (a) \\
\hline
\end{tabular}

(a) $\mathrm{P}$-value $<0.001$.

(b) In bold, coefficient statistically non-significant. 


\section{Figures}

Fig.1: Experimental system (1: Reactor, 2: UV lamp, 3: Air pump, 4: Cryostat, 5: Water inlet, 6: Water outlet, 7: Stirrer)

Fig.2: Predicted values compared with experimental results for both pollutants indole (a) and 4-methylphenol (b).

Fig.3: Interaction effects plot for removal indole

Fig.4: Interaction effects plot for removal 4-methylphenol

Fig.5: Graphs of surface and contours plots of indole removal (\%) showing interactive effect of two factors when the third is fixed at an average.

Fig.6: Graphs of surface and contours plots of 4-methylphenol removal (\%) showing interactive effect of two factors when the third is fixed at an average. 


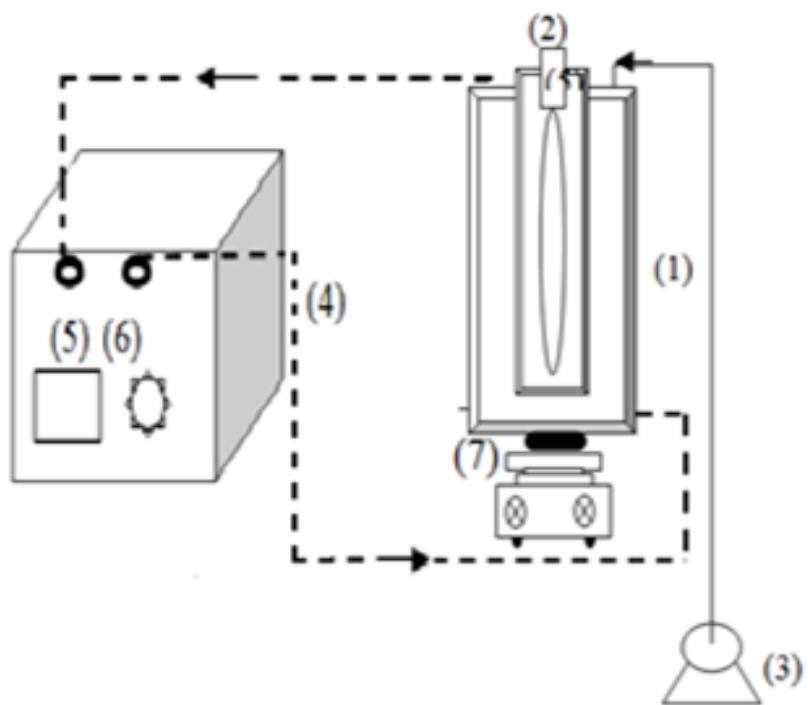

Fig. 1: Experimental system (1: Reactor, 2: UV lamp, 3: Air pump, 4: Cryostat, 5: Water inlet, 6: Water outlet, 7: Stirrer) 


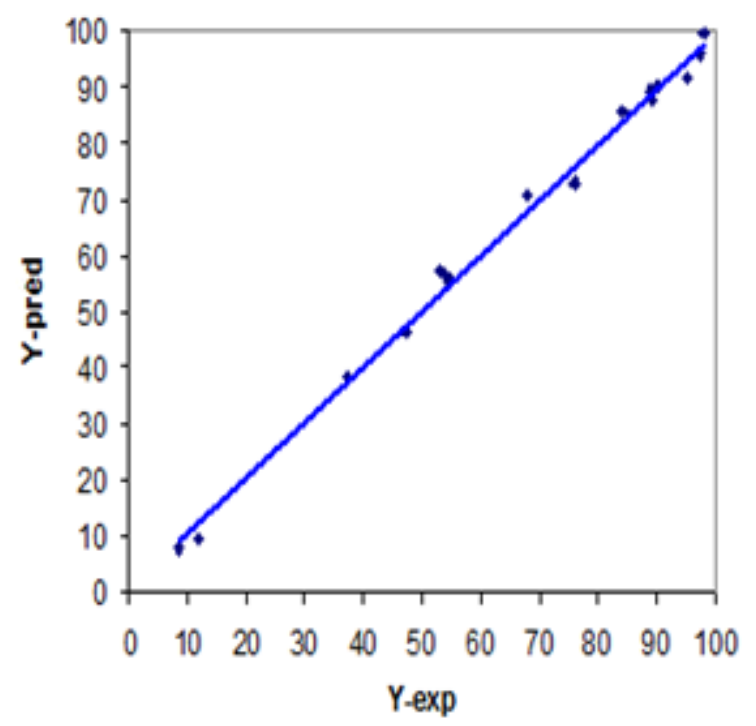

(a)

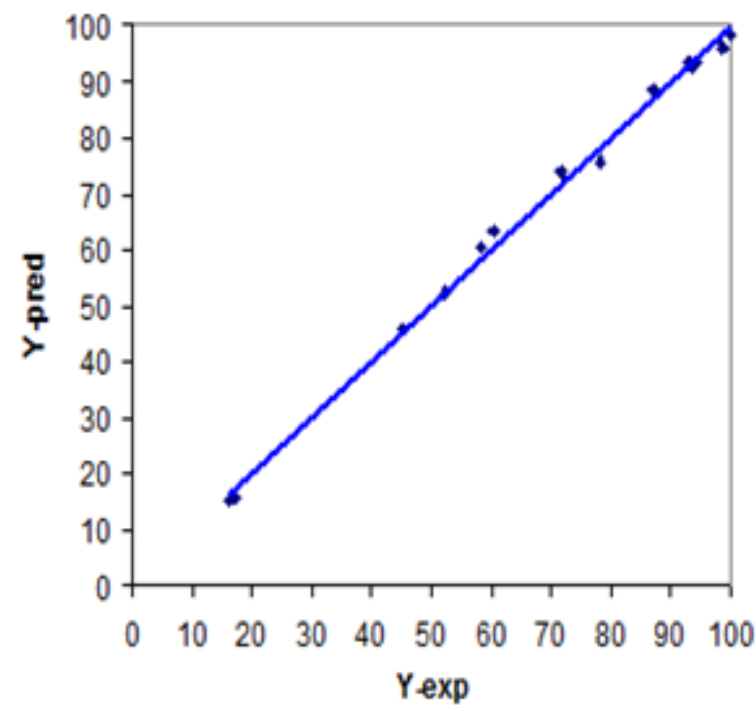

(b)

Fig. 2: Predicted values compared with experimental results for both pollutants indole (a) and 4-methylphenol (b). 


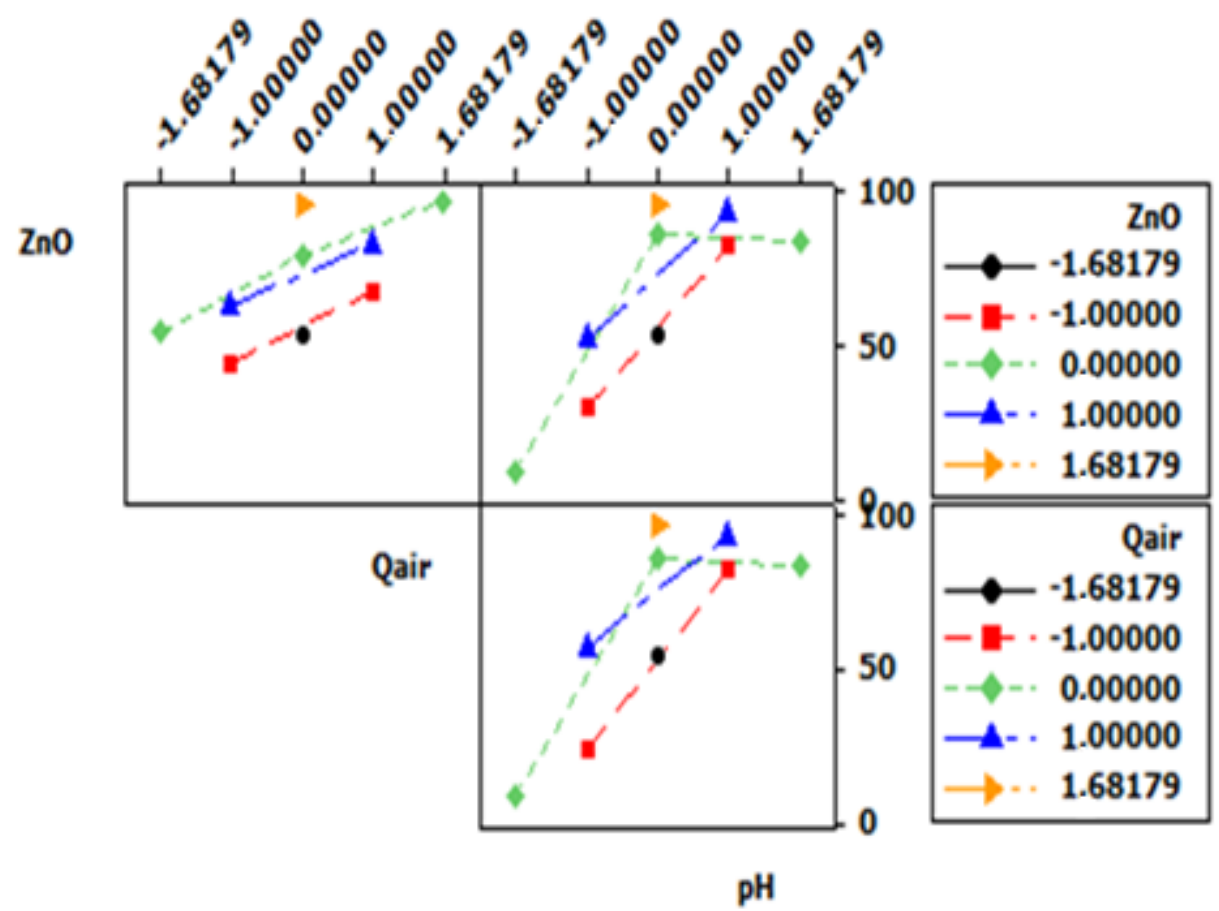

Fig.3: Interaction effects plot for indole removal 


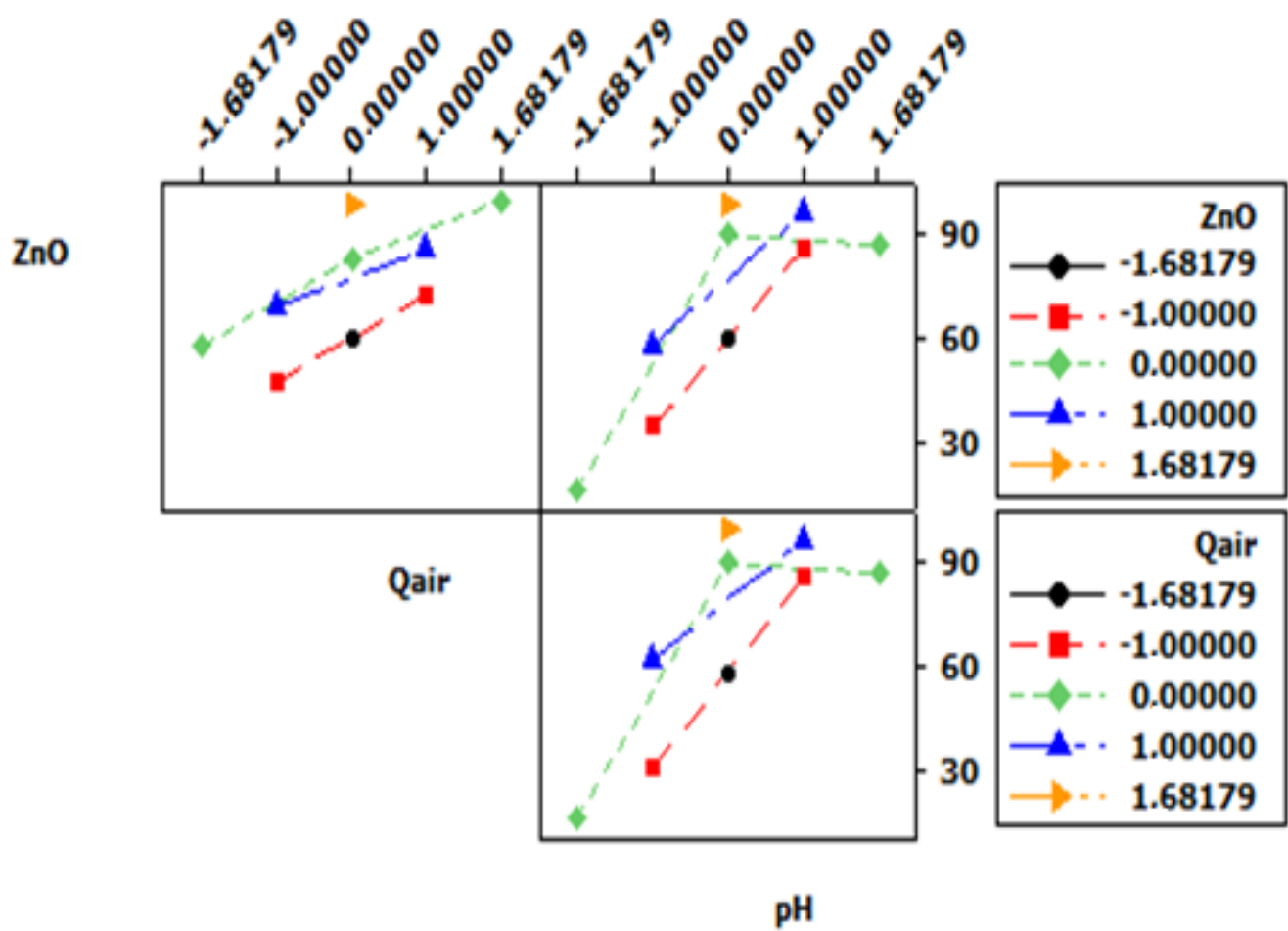

Fig.4: Interaction effects plot for 4-methylphenol removal 

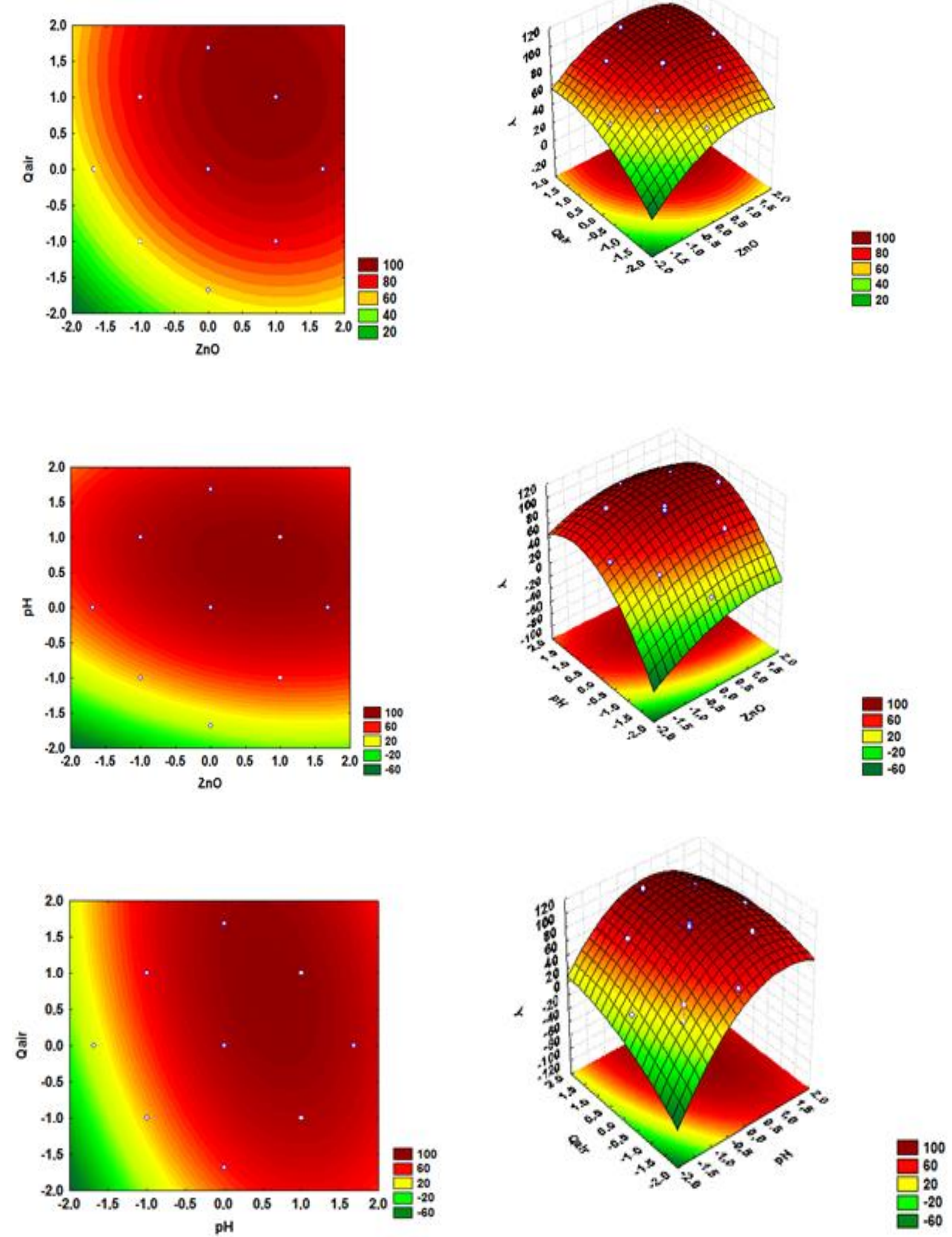

Fig.5: Graphs of surface and contours plots of indole removal (\%) showing interactive effect of two factors when the third is fixed at an average. 

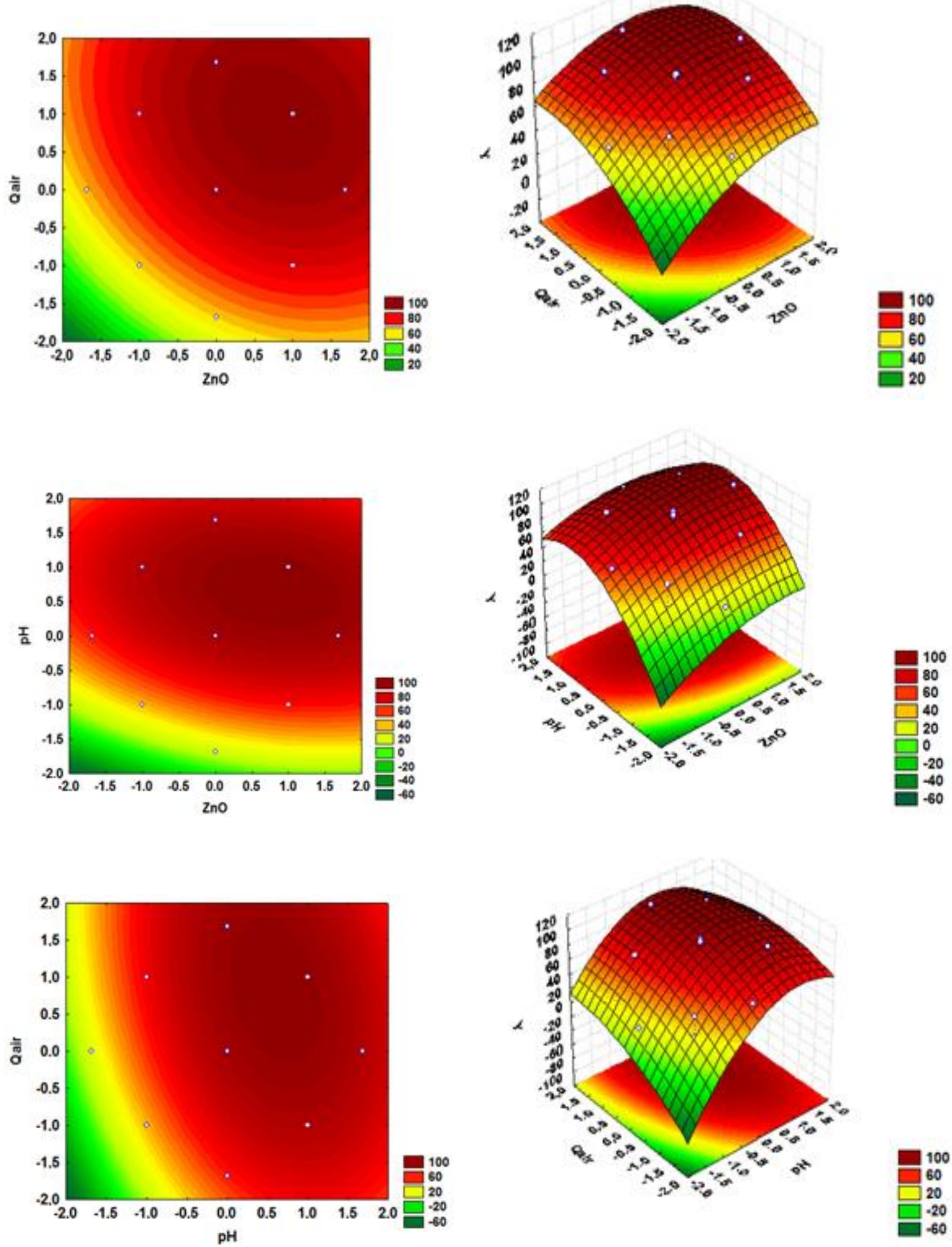

Fig.6: Graphs of surface and contours plots of 4-methylphenol removal (\%) showing interactive effect of two factors when the third is fixed at an average. 